\title{
Non-invasive EEG-based brain-computer interfaces in patients with disorders of consciousness
}

\author{
Emilia Mikołajewska ${ }^{1,2^{*}}$ and Dariusz Mikołajewski $i^{3,4,2}$
}

\begin{abstract}
Disorders of consciousness (DoCs) are chronic conditions resulting usually from severe neurological deficits. The limitations of the existing diagnosis systems and methodologies cause a need for additional tools for relevant patients with DoCs assessment, including brain-computer interfaces (BCls). Recent progress in $\mathrm{BCls}$ ' clinical applications may offer important breakthroughs in the diagnosis and therapy of patients with DoCs. Thus the clinical significance of $\mathrm{BCl}$ applications in the diagnosis of patients with DoCs is hard to overestimate. One of them may be brain-computer interfaces. The aim of this study is to evaluate possibility of non-invasive EEG-based brain-computer interfaces in diagnosis of patients with DOCs in post-acute and long-term care institutions.
\end{abstract}

Keywords: Neurological disorders, Disorders of consciousness, Brain-computer interfaces, EEG-based BCls

\section{Introduction}

Disorders of consciousness (DoCs) are chronic conditions resulting usually from severe neurological deficits. The most common are coma, vegetative state (VS)/unresponsive wakefulness syndrome, minimally conscious state (MCS, categorized recently into MCS + and MCS-), and locked-in syndrome (LIS) - constituting, according to some researchers, a continuum of consciousness. Patients with locked-in syndrome are considered as being fully conscious and therefore not part of patients with disorders of consciousness. LIS patients are fully conscious but unable to move and speak, so they can be diagnosed as VS patients. Damaged integration of system-level functional connectivity is perceived as one of the causes of DoCs. In VS and MCS the cause may be lack of external (perceptual) awareness, and internal (self-related) awareness related with the disruption of associated neural networks in selected brain areas, despite the preserved wakefulness networks of brainstem and basal forebrain [1-3]. But there is lack of one predominant paradigm in this

\footnotetext{
* Correspondence: e.mikolajewska@wp.pl

${ }^{1}$ Rehabilitation Department, Military Clinical Hospital No. 10 and Polyclinic, Powstańców Warszawy 5, Bydgoszcz 85-681, Poland

${ }^{2}$ Disorders of Consciousness Research and Neurorehabilitation Unit, Neurocognitive Laboratory, Centre for Modern Interdisciplinary Technologies, Nicolaus Copernicus University, Toruń, Poland

Full list of author information is available at the end of the article
}

area. This discrepancy results in severely decreased diagnostic accuracy and possible diagnostic mistakes. Moreover there is discussion even in the area of the number and names of DoCs [4-7]. Current diagnostic tools dedicated to patients with disorders of consciousness (e.g. unstandardized behavioral tests) seem to be insufficient, because such assessment relies mainly upon the subjective interpretation of observed behaviour.

The limitations of the existing diagnosis systems and methodologies should be detailed more. Observational diagnosis is based mainly by expertes on a list of items that the patient is unable to perform, thus is not objective (even $40 \%$ may need reclassification). Traditional methods and methodologias need improvement, then is neef for introducing more advanced, EEG-based or fMRI-based methods. EEG-based diagnosis is easy to set up, portable, widely available, practical for bedside testing, inexpensive, and provides very good temporal solution. Contrary fMRI (functional megnatic resonance imaging) is not portable and rather expensive, but has also non-invasive nature, and offers very good spatial resolution. But plastical changes caused by recovery process (e.g. in post-stroke patients) can provide activation patterns different from such patterns in healthy people, what makes challenge in analysis and interpretation. fNIRS (functional non-infrared spectroscopy) is more portable, low-noise, and artifact-sensitive 
than fMRI, and easier in everyday clinical use. But fNIRS is relatively new in BCIs applications, has limited depth of scanning (i.e. subcortical structures are hard to diagnose) and spatial resolution, and still needs for further research. Aforementioned limitations of the existing diagnosis systems and methodologies cause a need for additional tools for relevant patients with DoCs assessment [8], including brain-computer interfaces (BCIs). Clinical potential of current non-invasive EEG-based BCIs is not fully exploited, and need for further research on them should be emphasized. There is need for further technical development (signal gathering and processing, technical standarization, evaluation of commercial systems), standarized and wide accepted diagnostic battery. Thus evaluation of possibility of BCIs application in diagnosis of patients with DOCs in postacute and long-term care institutions still need for deeper research, clarification, and standarization, including clinical guidelines and procedures.

There are numerous healthcare problems, as far as ethical and social issues associated with DoCs, and there are additional issues associated with the therapy of patients with DoCs. Professionals working with patients with DoCs are at risk for developing burnout $[8,9]$. Families and caregivers of patients with DoCs may additionally show various negative conditions, e.g. prolonged grief disorder (PGD) [10]. Increased assessment possibilities may significantly influence problem-focused coping strategies in the aforementioned group of people.

$\mathrm{BCI}$ is a technology that can utilize various neural imaging/recording modalities including fMRI, EEG, and even invasive recording of brain activities. Research on non-invasive $\mathrm{BCIs}$ have made important demonstrations in controlling communication aids and external devices. The objective of this article is to evaluate the possibility of non-invasive brain-computer interface's application in the diagnosis of patients with DoCs in post-acute and long-term care institutions. The content of this research is regarded as very relevant to technological and clinical perspectives. BCIs allow for real-time converting of the brain's (bio)electrical activity into electrical signals for diagnosis, communication (using word processors or another dedicated software), and/or control (devices like neuroprostheses, wheelchairs, exoskeletons, etc., or even whole systems like smart home) purposes [11,12]. (Bio) electrical activity of the central nervous system (CNS) is converted to a control signal without any peripheral (nervous) and/or muscular activity. This feature is perceived as very important for BCIs' use in patients with DoCs.

\section{Material and methods}

Review was limited to non-invasive EEG-based braincomputer interfaces applied in patients with disorders of consciousness. A review of publications indexed in three main data bases (Pubmed - U.S. National Library of Medicine, PEDro - Physiotherapy Evidence Database, Health Source: Nursing/Academic Edition) was conducted using the specified keywords ("brain-computer inteface", "BCI", "EEG", "EEG-based", "non-invasive", "disorders of consciousness", "DoC", "coma", "locked-in", "vegetative state", "P300", and many more) as well as criteria of inclusion and exclusion (Table 1). The amount of BCI literature concerning both non-invasive and those using implantedelectrode interfaces is very large. Some BCI literature may not use the term DoC, but many papers mentioned fulfills specific conditions, including locked-in syndrome. Thus the search criteria may seem problematic, and the search keywords may seem problematic too.

The synthesis of the representative publications and systematic quantitative analysis of previous studies and study results was conducted with the aim of presenting the scope as well as the importance of current academic research and concepts.

Our aim is to sufficiently explore BCI applications in the diagnosis of DoCs and their clinical significance. The methodology of the other works, possibilities, requirements, difficulties and results are presented below.

\section{Results}

The authors conducted a search of three major databases using specified keywords and the aforementioned inclusion and exclusion criteria. The inclusion criteria was fulfilled by 29 publications for the years 2005-2014 (Table 2, Table 3).

The representative literature was synthesized to indicate the scope and weight of current knowledge and experience. As discussed in the early work of Kübler \& Neumann [20], the use of BCIs in severely paralyzed (locked-in) patients due to injury or disease is possible, but constitutes a huge challenge, and needs multidisciplinary research (comprising medical sciences, IT, biomedical engineering, cognitive sciences, psychology, etc.). According to Lehembre et al. [13], despite significant development of BCIs in the last twenty years there may be huge problems using them in patients with severe visual or auditory deficits, or severe lesions affecting their EEG signal. What is more, various etiologies of DoCs may additionally affect EEGs and/or Event Related Potentials (ERPs) in different ways [13]. Theses issues need further research. Even rather simple P300-based BCIs may be effective in behaviourally unresponsive patients [19]. There is no doubt in the potential for BCI's development, but the main limitations may be perceived as user training, simplicity, feedback, stimulation modality, sensitivity, and consistency [19]. As stated in the paper of Lulé et al. [14], only selected patients with MCS and LIS were able to use BCI based on the 4-choice auditory oddball EEG-BCI paradigm. Thus we should be aware that the proposed BCI's solution should be simplest 
Table 1 The inclusion and exclusion criteria adopted in the review

\begin{tabular}{cc}
\hline Inclusion criteria & Exclusion criteria \\
\hline published after 2000 & $\begin{array}{c}\text { published before 2000 } \\
\text { non-invasive EEG-based brain-computer interfaces } \\
\text { English, other languages if English abstract available } \\
\text { articles in reviewed journals }\end{array}$ \\
recommended for medical professions & $\begin{array}{r}\text { other kinds of non-invasive brain-computer interfaces, } \\
\text { including fMRI-based, NIRS-based, etc. } \\
\text { English abstract not available } \\
\text { articles in unreviewed journals }\end{array}$ \\
$\begin{array}{c}\text { editorial articles published in reviewed journals, letters to } \\
\text { the editor, dissertations, conference abstracts, summaries of } \\
\text { academic works, books or chapters in books }\end{array}$ & $\begin{array}{c}\text { articles directed towards representatives of professions not } \\
\text { connected with medical rehabilitation, e.g. sociologists etc. }\end{array}$ \\
\hline
\end{tabular}

Table 2 Articles included for review

\begin{tabular}{|c|c|c|}
\hline Name of journal & Number of publications & Authors \\
\hline Archives Italiennes de Biologie & 1 & Lehembre et al. 2012 [13] \\
\hline \multirow[t]{5}{*}{ Clinical Neurophysiology } & 5 & Lulé et al. 2013 [14] \\
\hline & & Sellers 2013 [15] \\
\hline & & Murguialday et al. 2011 [16] \\
\hline & & Kübler \& Birbaumer 2008 [17] \\
\hline & & Daltrozzo et al. 2007 [18] \\
\hline \multirow[t]{2}{*}{ Brain Injury } & 2 & Chatelle et al. 2012 [19] \\
\hline & & Cavinato et al. 2009 [20] \\
\hline \multirow[t]{3}{*}{ Progress in Brain Research } & 3 & Kübler \& Neumann 2005 [21] \\
\hline & & Sorger et al. 2009 [22] \\
\hline & & Pfurtscheller 2006 [23] \\
\hline Frontiers in Human Neuroscience & 1 & Risetti et al. 2013 [24] \\
\hline Clinical EEG and Neuroscience & 1 & Lugo et al. 2014 [25] \\
\hline Consciousness and Cognition & 1 & Tan et al. 2014 [26] \\
\hline \multirow[t]{2}{*}{ Annals of Neurology } & 2 & Naci et al. 2012 [27] \\
\hline & & Steppacher et al. 2013 [32] \\
\hline Conference Proceedings of the IEEE Engineering in Medicine and Biology Society & 1 & Eskandari \& Erfanian 2008 [28] \\
\hline Artificial Intelligence in Medicine & 1 & Pokorny et al. 2013 [29] \\
\hline Current Opinion in Neurology & 1 & Kübler \& Kotchoubey 2007 [30] \\
\hline Neuroimage: Clinical & 1 & Chennu et al. 2013 [31] \\
\hline PLos One & 1 & Cavinato et al. 2012 [33] \\
\hline Developmental Neurorehabilitation & 1 & Lancioni et al. 2011 [34] \\
\hline Neuroimage & 1 & Chica et al. 2010 [35] \\
\hline Journal of Cognitive Neuroscience & 1 & Van Gaal et al. [36] \\
\hline Cognitive and Behavioral Neurology & 1 & Daltrozzo et al.2009 [37] \\
\hline Neurocase & 1 & Schanakers et al. 2009 [38] \\
\hline Neurology & 1 & Schnakers et al. 2008 [39] \\
\hline International Journal of Rehabilitation Research & 1 & Uemura \& Hoshiyama 2007 [40] \\
\hline Neurocritical Care & 1 & Cruse et al. 2014 [41] \\
\hline Total & 29 & \\
\hline
\end{tabular}


(at the beginning, and then adoptable). On the other hand, only patients with completely locked-in syndrome (CLIS) are considered unable to use BCIs [15-17], but there still is an unusual case study by Schnakers et al. [38].

The diagnostic value of BCIs may be increased by the results that Mismatch Negativity (MMN) and P300 may be regarded as reliable predictors of awakening (conscious recovery) in low responsive patients [18,24,32-34,37,39], especially in patients in a vegetative state (VS) [21,27] or LIS [25]. A similar role may be played by N400 [28], N200 [36], or P100 [35]. However, in untrained patients in an acute phase of LIS, novel hemodynamically-based BCIs (using fMRI, and functional near-infrared spectroscopy fNIRS) may be predominant in the future [22].

The cortical activation model (CAM) by Pfurtscheller may improve the clinical significance of an event-related desynchronization (ERD) or event-related synchronization (ERS) in patients with DoCs [23].

Despite technical and clinical development BCIs for behaviourally unresponsive patients still present substantial challenges [27]. Preparation of the patient is important: mindfulness meditation training provided higher BCI accuracy compared to both the music training and no-treatment control groups [26,29]. Novel paradigms offer opportunities to support the clinical assessment of DoCs, including MCS [30]. A whole hierarchical procedure in the area of the assessment of the DoCs patient's cognitive abilities, consisting of passive stimulation, active instructions, volitional paradigms, and BCI operations was proposed by Kübler \& Kotchoubey [31]. Further research provided deeper insight into the nature and capabilities of attention in patients with DoCs [32], exogenous orienting [35], and the relationship between the level of consciousness and cognitive control (e.g. if cognitive control processes can be initiated unconsciously) [36], and semantic processing [37]. Changes of P300 in elderly patients with dementia described by Uemura \& Hoshiyama showed both novel possibilities of BCIs use and technical challenges [40].

\section{Discussion}

Considering all the manuscript, analysis of the topic is limited to research on non-invasive EEG-based braincomputer interfaces. This article is regarded as preliminary. Authors conduct own research on BCI applications in patients with DoCs within international InteRDoCTor (International-Interdisciplinary Research for Disorders od Consciousness in Toruń) research team. Results of the research will be published elsewhere.

Analysis of published findings up to this point supports the hypothesis that further application of BCIs in patients with DoCs may have an important positive influence on diagnostic precision and its features (e.g. its inter-rater reliability), and, as a result, may positively influence outcomes of the therapy (including rehabilitation). The main challenges both for scientists, engineers, and clinicians are as follows:

- easy training (or no-training) tools for the most severe cases of BCIs,

- clinical procedures of BCIs installation or implantation, including indications and contraindications, 
- clinical procedures and guidelines for non-invasive BCIs' application for diagnostic purposes, including supplementary BCIs' use with fMRI, PET, conventional EEG, etc.

- patient safety precautions, including possible threats and effects of long-term BCI use,

- ethical and legal problems, e.g. concerning the balance between human intent and its interpretation by BCIs' software within the decision-making process,

- newest diagnostic tools and research methodologies according to the Evidence Based Medicine paradigm, including magnetoencephalography (MEG),

- whole families of scalable BCI devices and systems, depending on DoCs' etiology, location(s) of lesion(s), patients' clinical status, preserved cognitive functions, etc. (from simple yes/no communication to complex systems for communication and control).

Existing research has not sufficiently solved the aforementioned issues. The increased effectiveness of the therapy, the shortening of the hospitalization period, and significantly increasing the quality of life of patients with DoCs and their families/caregivers is worth every effort in the aforementioned area. The application of aforementioned occupations in a group of new medical services (telemedicine, telerehabilitation), and within an eclectic/mixed approach to intervention in neurorehabilitation seems to be obligatory.

\section{Conclusions}

Recent progress in clinical applications of the noninvasive EEG-based BCI's may offer important breakthroughs in the diagnosis and therapy of patients with DoCs, especially compared with traditional observational diagnosis. There is a need for further research concerning clinical application of non-invasive EEG-based BCIs' for diagnosis, and, where possible, communication and control purposes. Implementing more sophisticated data analysis methods and neurofeedback training techniques may be necessary [22]. This approach still needs additional research. Moreover it is not accurate to say that current "traditional" diagnostic approaches to diagnosis in DoCs are not sufficient for managing DoC patients, and fMRI, fNIRS, MEG, etc. will be much better. It seems that a complex approach joining several diagnostic methods, techniques, and tools may dramatically increase the exactness of the diagnosis in patients with DoCs. Such hybrid solutions (incorporating e.g. noninvasive EEG-based BCl's and fMRI) [42] are perceived important direction of further research within clinical application of BCIs in DoCs patients. Basic research on neuroimaging and electophysiology in patients with
DOC may constitute a solid basis for further clinical research on identifying more advanced physiological and computational measures closely associated with level of consciousness [43-45].

\section{Competing interests}

The authors declare that they have no competing interests.

\section{Authors' contributions}

EM carried out the review and drafted the manuscript. EM carried out the review and drafted the manuscript. All authors read and approved the final manuscript.

\section{Authors' information}

Emilia Mikołajewska: http://www.emikolajewska.netstrefa.eu/.

\section{Acknowledgements}

Article is a part of research conducted by the author within international InteRDoCTor (International-Interdisciplinary Research for Disorders od Consciousness in Toruń) research team http://www.interdoctor.umk.pl/.

\section{Author details}

${ }^{1}$ Rehabilitation Department, Military Clinical Hospital No. 10 and Polyclinic, Powstańców Warszawy 5, Bydgoszcz 85-681, Poland. ²Disorders of Consciousness Research and Neurorehabilitation Unit, Neurocognitive Laboratory, Centre for Modern Interdisciplinary Technologies, Nicolaus Copernicus University, Toruń, Poland. Institute of Mechanics and Applied Computer Science, Kazimierz Wielki University, Bydgoszcz, Poland.

${ }^{4}$ Department of Applied Informatics, Department of Physics, Astronomy and Applied Informatics, Nicolaus Copernicus University, Toruń, Poland.

Received: 4 May 2014 Accepted: 12 June 2014

Published: 14 July 2014

\section{References}

1. Demertzi A, Soddu A, Laureys S: Consciousness supporting networks. Curr Opin Neurobiol 2012. 23(2):239-44.

2. Vanhaudenhuyse A, Noirhomme Q, Tshibanda LJ, Bruno MA, Boveroux P, Schnakers C, Soddu A, Perlbarg V, Ledoux D, Brichant JF, Moonen G, Maquet $P$, Greicius MD, Laureys S, Boly M: Default network connectivity reflects the level of consciousness in non-communicative brain-damaged patients. Brain 2010, 133(Pt 1):161-171.

3. Mikołajewska E, Mikołajewski D: Consciousness disorders as the possible effect of brainstem activity failure - computational approach. $J$ Health SS 2012, 2(2):7-18.

4. Boly M, Seth AK: Modes and models in disorders of consciousness science. Arch Ital Biol 2012, 150(2-3):172-84

5. Machado C, Estévez M, Carrick FR, Rodríguez R, Pérez-Nellar J, Chinchilla M, Machado Y, Pérez-Hoz G, Carballo M, Fleitas M, Pando A: Vegetative state is a pejorative term. NeuroRehabilitation 2012, 31(4):345-347.

6. Bruno MA, Vanhaudenhuyse A, Thibaut A, Moonen G, Laureys S: From unresponsive wakefulness to minimally conscious PLUS and functional locked-in syndromes: recent advances in our understanding of disorders of consciousness. J Neurol 2011, 258(7):1373-84

7. Gosseries O, Bruno MA, Chatelle C, Vanhaudenhuyse A, Schnakers C, Soddu A, Laureys S: Disorders of consciousness: what's in a name? NeuroRehabilitation 2011, 28(1):3-14.

8. Guldenmund P, Stender J, Heine L, Laureys S: Mindsight: diagnostics in disorders of consciousness. Crit Care Res Pract. 2012, 2012:624724.

9. Matilde L, Marco P, Mara GA, Alberto R, Alberto R: Burnout in healthcare professionals working with patients with disorders of consciousness. Work 2013, 45(3):349-56.

10. de la Morena MJ, Cruzado JA: Caregivers of patients with disorders of consciousness: coping and prolonged grief. Acta Neurol Scand 2013. doi:10.1111/ane.12061.

11. Mikołajewska E, Mikołajewski D: Technical and medical problems concerning wider use of neuroprostheses in patients with neurologic disorders. Pielęgniarstwo Neurologiczne i Neurochirurgiczne 2012, 1(3):119-23.

12. Mikołajewska E, Mikołajewski D: Neuroprostheses for increasing disabled patients' mobility and control. Adv Clin Exp Med 2012, 21(2):263-72. 
13. Lehembre R, Gosseries O, Lugo Z, Jedidi Z, Chatelle C, Sadzot B, Laureys S, Noirhomme Q: Electrophysiological investigations of brain function in coma, vegetative and minimally conscious patients. Arch Ital Biol 2012 150(2-3):122-39.

14. Lulé D, Noirhomme Q, Kleih SC, Chatelle C, Halder S, Demertzi A, Bruno MA, Gosseries O, Vanhaudenhuyse A, Schnakers C, Thonnard M, Soddu A, Kübler A, Laureys S: Probing command following in patients with disorders of consciousness using a brain-computer interface. Clin Neurophysio/ 2013, 124(1):101-6.

15. Sellers EW: New horizons in brain-computer interface research. Clin Neurophysiol 2013, 124(1):2-4

16. Murguialday AR, Hill J, Bensch M, Martens S, Halder S, Nijboer F, Schoelkopf B, Birbaumer N, Gharabaghi A: Transition from the locked in to the completely locked-in state: a physiological analysis. Clin Neurophysiol 2011, 122(5):925-33.

17. Kübler A, Birbaumer N: Brain-computer interfaces and communication in paralysis: extinction of goal directed thinking in completely paralysed patients? Clin Neurophysiol 2008, 119(11):2658-66.

18. Daltrozzo J, Wioland N, Mutschler V, Kotchoubey B: Predicting coma and other low responsive patients outcome using event-related brain potentials: a meta-analysis. Clin Neurophysiol 2007, 118(3):606-14.

19. Chatelle C, Chennu S, Noirhomme Q, Cruse D, Owen AM, Laureys S: Brain-computer interfacing in disorders of consciousness. Brain Inj 2012, 26(12):1510-22.

20. Cavinato M, Freo U, Ori C, Zorzi M, Tonin P, Piccione F, Merico A: Post-acute P300 predicts recovery of consciousness from traumatic vegetative state. Brain Inj 2009, 23(12):973-80.

21. Kübler A, Neumann N: Brain-computer interfaces - the key for the conscious brain locked into a paralyzed body. Prog Brain Res. 2005 150:513-25

22. Sorger B, Dahmen B, Reithler J, Gosseries O, Maudoux A, Laureys S, Goebel $\mathrm{R}$ : Another kind of 'BOLD Response': answering multiple-choice questions via online decoded single-trial brain signals. Prog Brain Res. 2009, 177:275-92.

23. Pfurtscheller G: The cortical activation model (CAM). Prog Brain Res. 2006, 159:19-27.

24. Risetti M, Formisano R, Toppi J, Quitadamo LR, Bianchi L, Astolfi L, Cincotti F, Mattia D: On ERPs detection in disorders of consciousness rehabilitation. Front Hum Neurosci. 2013, 7:775

25. Lugo ZR, Rodriguez J, Lechner A, Ortner R, Gantner IS, Laureys S, Noirhomme Q, Guger C: A vibrotactile p300-based brain-computer interface for consciousness detection and communication. Clin EEG Neurosci 2014, 45(1):14-21.

26. Tan LF, Dienes Z, Jansari A, Goh SY: Effect of mindfulness meditation on brain-computer interface performance. Conscious Cogn. 2014, 23:12-21.

27. Naci L, Monti MM, Cruse D, Kübler A, Sorger B, Goebel R, Kotchoubey B, Owen AM: Brain-computer interfaces for communication with nonresponsive patients. Ann Neurol 2012, 72(3):312-23.

28. Steppacher I, Eickhoff S, Jordanov T, Kaps M, Witzke W, Kissler J: N400 predicts recovery from disorders of consciousness. Ann Neurol 2013, 73(5):594-602.

29. Eskandari $\mathrm{P}$, Erfanian A: Improving the performance of brain-computer interface through meditation practicing. Conf Proc IEEE Eng Med Biol Soc. 2008, 2008:662-5.

30. Pokorny C, Klobassa DS, Pichler G, Erlbeck H, Real RG, Kübler A, Lesenfants D, Habbal D, Noirhomme Q, Risetti M, Mattia D, Müller-Putz GR: The auditory P300-based single-switch brain-computer interface: paradigm transition from healthy subjects to minimally conscious patients. Artif Intell Med 2013, 59(2):81-90.

31. Kübler A, Kotchoubey B: Brain-computer interfaces in the continuum of consciousness. Curr Opin Neurol 2007, 20(6):643-9.

32. Chennu S, Finoia P, Kamau E, Monti MM, Allanson J, Pickard JD, Owen AM, Bekinschtein TA: Dissociable endogenous and exogenous attention in disorders of consciousness. Neuroimage Clin. 2013, 3:450-61.

33. Cavinato M, Rigon J, Volpato C, Semenza C, Piccione F: Preservation of auditory P300-like potentials in cortical deafness. PLoS One 2012, 7(1):e29909.

34. Lancioni G, Singh N, O'Reilly M, Olivetti M, de Tommaso M, Navarro J, Colonna F, Lanzilotti C, Buonocunto F, Sacco V: A learning assessment procedure as a test supplement for monitoring progress with two post-coma persons with a diagnosis of vegetative state. Dev Neurorehabil 2011, 14(6):358-65.

35. Chica AB, Lasaponara S, Lupiáñez J, Doricchi F, Bartolomeo P: Exogenous attention can capture perceptual consciousness: ERP and behavioural evidence. Neuroimage 2010, 51(3):1205-12.

36. van Gaal S, Lamme VA, Fahrenfort JJ, Ridderinkhof KR: Dissociable brain mechanisms underlying the conscious and unconscious control of behavior. J Cogn Neurosci 2011, 23(1):91-105.

37. Daltrozzo J, Wioland N, Mutschler V, Lutun P, Calon B, Meyer A, Pottecher T, Lang S, Jaeger A, Kotchoubey B: Cortical information processing in coma. Cogn Behav Neurol 2009, 22(1):53-62.

38. Schnakers C, Perrin F, Schabus M, Hustinx R, Majerus S, Moonen G, Boly M, Vanhaudenhuyse A, Bruno MA, Laureys S: Detecting consciousness in a total locked-in syndrome: an active event-related paradigm. Neurocase 2009, 15(4):271-7.

39. Schnakers C, Perrin F, Schabus M, Majerus S, Ledoux D, Damas P, Boly M, Vanhaudenhuyse A, Bruno MA, Moonen G, Laureys S: Voluntary brain processing in disordes of consciousness. Neurology 2008, 71(20):1614-20.

40. Uemura J, Hoshiyama M: Variability of P300 in elderly patients with dementia during a single day. Int J Rehabil Res 2007, 30(2):167-70.

41. Cruse D, Norton L, Gofton T, Young GB, Owen AM: Positive Prognostication from Median-Nerve Somatosensory Evoked Cortical Potentials. Neurocrit Care 2014, DOl:10.1007/s12028-014-9982-y.

42. Cruse D, Gantner I, Soddu A, Owen AM: Lies, damned lies and diagnoses: Estimating the clinical utility of assessments of covert awareness in the vegetative state. Brain Inj. 2014, 9:1-5.

43. Goldfine AM, Schiff ND: What is the role of brain mechanisms underlying arousal in recovery of motor function after structural brain injuries? Curr Opin Neurol 2011, 24(6):564-9.

44. Goldfine AM, Schiff ND: Consciousness: its neurobiology and the major classes of impairment. Neurol Clin 2011, 29(4):723-37.

45. Goldfine AM, Victor JD, Conte MM, Bardin JC, Schiff ND: Bedside detection of awareness in the vegetative state. Lancet 2012, 379(9827):1701-2.

doi:10.1186/2054-9369-1-14

Cite this article as: Mikołajewska and Mikołajewski: Non-invasive EEG-based brain-computer interfaces in patients with disorders of consciousness. Military Medical Research 2014 1:14.

\section{Submit your next manuscript to BioMed Central and take full advantage of:}

- Convenient online submission

- Thorough peer review

- No space constraints or color figure charges

- Immediate publication on acceptance

- Inclusion in PubMed, CAS, Scopus and Google Scholar

- Research which is freely available for redistribution

Submit your manuscript at www.biomedcentral.com/submit
C) BioMed Central 